\title{
Strategies for Translation of English Commercial Advertisements from the Intercultural Perspective
}

\author{
Hui Fan \\ School of Foreign Studies, Yangtze University, Jingzhou, China \\ Email: fanhui@yangtzeu.edu.cn
}

How to cite this paper: Fan, H. (2017) Strategies for Translation of English Commercial Advertisements from the Intercultural Perspective. Open Journal of Social Sciences, 5, 38-45.

https://doi.org/10.4236/jss.2017.511004

Received: October 11, 2017

Accepted: November 5, 2017

Published: November 8, 2017

Copyright $\odot 2017$ by author and Scientific Research Publishing Inc. This work is licensed under the Creative Commons Attribution-NonCommercial International License (CC BY-NC 4.0).

http://creativecommons.org/licenses/by-nc/4.0/

\begin{abstract}
With the development of economic globalization, advertising industry has been developing at a speed no one could imagine twenty years ago. This paper focuses on the research of advertising translation with the directions of intercultural interaction and western translation theories. What is more, it provides several effective strategies and vivid instances in advertising practice. The research indicates that according to the features of ads, proper methods can be utilized in the process of translation.
\end{abstract}

\section{Keywords}

Commercial Advertising, Cross-Culture, Translation, Strategies

\section{Introduction}

As the development of global business and trade continues to grow, the economic exchanges between countries and regions are becoming increasingly common, and advertising is playing an important role in the international commodities economy. In terms of the study of the translation with regards to commercial advertising, most scholars have probed from the point of view of linguistics or translation theories. Some scholars like Quan $\mathrm{Lu}$ [1] discussed this issue based on Nida Eugene A's theory of functional equivalence in 2000. In his paper "Alternative Ways in the Translation of Advertising Discourse between English and Chinese", Quan Lu believes that the translation of the advertisement should be in the target language of the reader and should produce an effect or message that comes closest to replicating the original intended message of the original text of the reader through a flexible way of functional equivalence and 
advertising discourse rules [1]. Some other scholars like Weiguo Tan [2], in his "Translation of Rhetorical Constructs in Advertising Discourse between English and Chinese", attempt to prove the importance of appropriate text and the freedom to choose the method at the word and sentence level, in the light of the functions a particular rhetorical construct performs and the explicit and implicit meaning it tries to convey, for quality control in translating advertisements between the two languages. There are also scholars who focus their attention on the emotion transfer of advertising translation. For example, Wenbo Jia [3] discusses in his paper "On the Emotion Conveyance of Ad Translation", which lists many examples about effective communication, and claims that in advertising translation, the translator should focus on the emotional transfer, rather than just producing a semantic equivalent.

Advertising language is a unique form of practical writing, and often differs from ordinary literary works. Advertising translation is not only a linguistic activity, but should also be a practice necessary to any business interested in expanding into foreign markets. Therefore, the debate arises between the differences in advertising translations versus literal translations, and in what ways does culture have an impact on commercials and which translation strategies for commercial ads from an intercultural perspective have been determined.

Errors in the translation of brand names, packaging copy, and advertising messages have cost millions of dollars, not to mention damaging their credibility and reputation. Advertising translation has become increasingly important for today's globalization of products and service. Also it is a new area for today's translation studies. "In the training of translators, very little attention has been paid to the translation of advertisements. Yet this type of translation has been far more widespread than that is immediately obvious" [4]. There are few systematic or practical translation theories for advertisement translation so far. However, many scholars who have paid attention to advertisement translation have agreed on one important thing: "What poses major obstacles for efficient translations is not only the language but primarily cross-cultural unawareness" [5].

This paper aims to give insight into these questions and the author hopes to contribute to strategies for translation from English commercial advertisements to Chinese commercial advertisements from intercultural perspective. And it will also help to analyze the influence of cultural differences on the translation of commercial ads, and provide strategies that can be employed. Here we use E-C to replace English to Chinese; this form is followed by the whole paper.

\section{Strategies for English-Chinese Translation of Commercial Advertising from Intercultural Perspective}

Language is aimed at a target audience. The function and focus of the advertising language determines the characteristics of the advertising language [6]. It is clear that the foremost purpose of advertising is to make consumers more susceptible to a product or service. Inappropriate commercial translation can lead 
to marketing failure. Therefore, how to translate advertisements will become a necessary and important subject. Translators often have a hold of their own ideas in regards to advertising translation. For different translating methods, different translators have different translating strategies on advertising. Some translators believe that the standard of translation is authenticity and accuracy. The translation should strive to be consistent with the original one to make it easier for the target audience to understand. Others argue that advertising should be translated in abstract and graceful words so that consumers can be more likely to be attracted. On this basis, we can find the key to advertising translation is to master the translation of the various skills.

When people discuss commercial advertising translation, faithfulness is no longer the only principle. After the above analysis, the purpose of commercial advertising translation is to effectively communicate and realize the purchase action. For the sake of achieving this ideal purpose, the following translation strategies can be used as a reference.

\subsubsection{Literal Translation}

Larson [7] published Meaning-based Translation: A Guide to Cross-language Equivalence in 1984, in which he stated "A literal translation is a translation that follows closely the form of the source language."

In literal translations, the translation must contain both the original content and keep the original form, as it should be subjected to the literal translation in regards to the target language and not be influenced by subjective interpretations; the translation not only retains the original contents, but also the original forms, especially retains the metaphors, figures and tastes, etc.

For instance, “Challenge the limits” (translation: “挑战极限”). This is the advertisement of SAMSUNG. This literal translation just uses four Chinese words to express a concise meaning. A brief advertisement that contains uncomplicated contents can be translated in the way of literal translation. However, when doing the translation, people must take into account cultural differences among different nations in which the exporters need to do research whether the sentences have positive meanings as well in foreign countries. Take another advertisement from KODAK for example “Kodak is Olympic Color” (translation: “柯达，奥林 匹克的色彩”). On hearing the Olympic color, individuals tend to associate brilliant five-ring flag and athlete of different skin color. The contrast of Kodak film to the Olympic color leads individuals to the conclusion that this brand is the leading producer compared with other companies. And there are so many examples such as NESCAFE for example “the taste is great” (translation: “味道好 极了”) and so on.

A literal translation is the rendering of text from one language to another "word-for-word" rather than conveying the sense of the original. If handled properly, literal translations can not only be loyal to the source language, but also reflect the incisiveness and prettiness of the original sentence, which makes the translation of the advertisement easy to understand. 


\subsubsection{Free Translation}

According to Peter [8], a free translation is usually paraphrased from its original context, and for free translation, it often won't concern about manner matters.

In many cases, the literal translation cannot convey the entirety of its message well. If used inappropriately, the original sense and message could be destroyed, thus making things worse. Therefore, free translation was introduced in order to compensate for the drawbacks of literal translation. “光临风韵之境一一万宝路 世界” is translated from “come to where the flavor is, Marlboro country”, which is Marlboro's cigarette advertisement. Marlboro projects the American cowboy image. The word of "Marlboro" symbolizes freedom, and being unrestrained. "Flavor" means "fragrance" whose smell is produced by the lit cigarettes. Translations for "charm and nature" and "flavor" were evident. In a smoke-filled environment, characterized by rich flavored tobacco, smokers will feel very relaxed and free, as if coming to a vast wilderness, riding stoically and freely. McDonald also give us a good example whose advertisement is "Good time, Great taste" (translation: “麦当劳-美好时光, 美味共享”). This target slogan expresses the original implication, what's more, it also retains the made of antithesis. That's why this advertisement is regarded as a representative model of free translation.

Free Translation differs from literal translation as the former focuses on implication of the source language rather than the original sentence structure or literal meaning. Moreover, free translation is used when culture-related items have different meanings in Western and Chinese cultures, resulting in the change of image or even the change of the whole sentence structure while translating.

\subsubsection{Creative Translation}

Creative translation means the rendering the advertisement or message which is beyond the translation concept by creative approaches. For meeting the requirement of the purchasers and increasing economic efficiency, the interpreters should enable the translated text to conform to the target culture and custom [9].

In order to meet the requirements of the potential consumers and enhance product selling, translators should attempt to adapt their translation to meet the target audience's culture and language habits. Thus, during the process of advertising translation, the translators are supposed to use their creativity to make the translation more attractive, often suiting the preference of the target readers. So we can say creative translation refers to the rendition that is already out of the translation category with creativity. Practice has proved that it is an effective advertising translation strategy. It was developed to compliment the first two translation strategies.

Take Nokia mobile phones for an example. Its English advertising is "Connecting People." which is well-known among countries that speak English; however, in China we translate that into “科技以人为本”. Therefore when we see this advertisement for the first time, the word “科技” catches our eyes im- 
mediately. The reason is during recent years, the term "technology" is widely used in our country and recognized by almost everyone in our country. They also realize that "technology is the first productive force" which can make our country stronger. Many idioms are familiar by consumers in China, so it is not difficult for advertisers to adapt their advertising to the idioms that are widespread, to take advantage of Chinese tendencies to use idioms in their daily lives to express their feelings. The innovated utilization of idioms could grant them with new opportunities which could make them notable and competitive. The source slogan cannot be translated to “联系人们” literally, but translate that into an innovative way “以人为本”.

\subsubsection{Adaptation Translation}

Eugene A. Nida assumes: "whatever in which translation, there will be a 'missing' type of semantic content, but the process should be so designed to minimize it." [10]. Loss of semantic content can be accredited to the differences in cultures between different countries. Adaptation can be understood as a set of translation operations, which leads to a text that is not accepted as a translation. By adaptation, the translator can make a huge change to the source text based on the content and form. In order to make advertising translation more readable and attractive, translators are free to convert the original expression into a better form of the target language. This technique is usually used in ad translation. Consider the following for examples:

CHINA-SILK ROAD TO OLYMPIC GOLD

(translation: 中国一一从古丝绸之路的文明到北京奥运的辉煌)

CHINA-MORE THAN A GREAT WALL

(translation: 中国一一不止万里长城)

The two advertisements are collected by China National Tourist Office about Chinese tourism image. They're wonderful advertisements which can satisfy foreigners' interest in Chinese history and culture. This translator has translated Chinese tourism's image in less than six words. From these six words, people could gain insights into China's history, art, scenic spots, value, etc.

The above two advertisements have witnessed the development of China's foreign tourism and the promotion of culture. After 30 years of reform and opening up policy efforts, westerners can better and more easily understand the Chinese culture. Particularly after Beijing Olympic Games, the experience of Chinese culture has risen to new heights.

Remy Martin XO_Exclusively Fine Champagne Cognac.

(translation: 人头马一开, 好事自然来.) (Remy Martin XO 人头马)

The original text is only a brief description of this champagne which is a kind of Cognac, a famous wine in France and the advertiser just employs a simple adjective to define its quality. While translating it, the translator abandons the original structure and uses parallelism and rhyme (“开” and “来”). The Chinese version sounds very passionate and very smooth to read.

My goodness! My Guinness! 
Edition 1: 我的上帝! 我的 Guinness 酒!

Edition 2: 此酒只应天上有!

The first edition is the literal translation of the original advertisement, which sounds unnatural to the Chinese readers. While in edition 2, “此酒只应天上有” is from Chinese famous poet Li Bai, which is very easy to arouse the desire of Chinese consumers to try this wine.

\subsubsection{Idioms Translation}

Idiom is the meaning of a group of words which is different from the meaning of a single word. The use of idioms in translation can compensate for differences in Chinese and Western culture and make translation more attractive to target customers. For instance, “Good to the last drop” is translated as “滴滴香浓, 意 犹未尽” from a Maxwell House coffee commercial advertisement. In this advertisement, the translator used psychological knowledge to provide consumers with psychological feelings of service. Based on advertising, "last drop" means "spread". However, the translator added "something more to say" to this idiom. It extended the original psychological feelings of advertising and heightened the effects of the message.

The practice of using imitation in translations involves the use of idioms that are familiar to the audience's fixed expression as a way to convey messages from the source text. The particularity of commercial advertising determines that the translator should use all possible means to achieve the intended function of the target text. Imitation comes from parody, one of the rhetoric devices. It's a very useful way for advising translation when the original form must be changed in the target text. In the target culture, through the use of popular words, proverbs, poetry, etc., advertising can bridge the gap between advertisers and consumers, in an attempt to achieve the desired goal. Take the following sentences as examples:

Apple Think Different.

(translation: 不同凡想)

The only thing we didn't improve was the road.

(translation: 万事具备, 只看路况)

The above two advertisements utilize idioms as a translation strategy. Chinese four words proverb “不同凡响” is imitated here to translate into the translated version of example 1. “不同凡响” is always used to describe things which are extraordinary and excellent. “想” refers to using mind to think. Apple Company adjusted this Chinese idiom into their advertisement, not only to achieve the idea of Apple's innovative ideas, but also try to establish goodwill from Chinese consumers as the message resonated with the target audience. As for the example 2, it is imitated from a familiar Chinese idiom “万事具备, 只欠东风”. Through the deliberate imitation of the existing language form or information in the target language, the new language material becomes more fluent and moving. Obviously, the use of idioms is an effective way to attract the target audience. 
In the target language, especially in Chinese language, there are a lot of idioms. Whether they are Chinese proverbs or slang, idioms are very popular among them. Therefore, in the translation process, the translator is more inclined to use idioms as a tool to attract a wider audience.

\section{Conclusions}

Advertising has become a very important and necessary tool of spreading information and creating a brand in target market. Nowadays, any economic activity which is out of the form of advertising campaigns rarely can reach to great success. Meanwhile, the importance of commercial advertising translation has also increased. Advertising is not only a cultural exchange, but also an economic activity. As a cultural exchange, its function provides updated information and knowledge, and creates and spreads positive cultural images and ideas. On the other hand, it is an economic activity that has an identifiable commercial purpose.

In summary, from the perspective of cross-cultural communication, translation of English-Chinese commercial advertisements involves the following aspects: values difference, social custom difference, language difference, geographical and humanistic environment difference. At the same time, the proposed strategies include: a simple and clear literal translation, understanding and profound free translation, innovative creative translation, adaptation translation which is applied to the context, and idioms translation of Chinese idioms. Any of the previously mentioned translation strategies can be selected according to different circumstances, but no matter what translation strategy is chosen, it must be tailored to the Chinese audience and consumer psychology. We can come into the following conclusion: by the previous more background information of features and cultures, it will be helpful to better comprehend the advertising language in order to have access to the creation of successful advertising translation. Due to differences in cultures and cultural properties of advertising, the translation encounters many difficulties. An advertisement contains different cultural factors such as language, values, history and customs which must be dealt with in the translation process with regard to advertising effect of cross-cultural communication. Therefore, advertising translation is also a cross-cultural communication. The translator should not only convey the meaning of ad, but also take the culture factors into consideration, because bicultural is more important than bilingual for a successful translator. I hope this paper can provide a frame of reference for Chinese translators and copywriters, and can have some practical value at a time when China is about to rapidly incorporate into the international market in terms of advertising.

\section{References}

[1] Lu, Q. (2000) The Language of Metaphors. Routledge, London and New York.

[2] Tan, W.G. (2003) Translation of Rhetorical Constructs in Advertising Discourse between English and Chinese. Chinese Translation Journal March, 24, No. 2. 
[3] Jia, W.B. (1996) On the Advertising Translation of Emotion Conveyance. Journal of Foreign Languages, No. 2, 57-60.

[4] Smith, V. and Klein, M. (1997) Advertising-A Five-Stage Strategy for Translation. Translation as Intercultural Communication. https://doi.org/10.1075/btl.20.18smi

[5] Jettmarova, Z. and Piotrowska, M. (1997) New Advertising Markets as Target Areas for Translation. Research Gate. https://doi.org/10.1075/btl.20.19jet

[6] Ouyang, X.L. (2009) On Strategies for English-Chinese Translation of Commercial Advertising. Journal of Language and Literature Studies, 2.

[7] Larson, M.L. (1984) Meaning-Based Translation: A Guide to Cross-Language Equivalence. University Press of America, Lanham, MD.

[8] Peter, N. (2001) Approaches to Translation. Shanghai Foreign Language Education Press, Shanghai.

[9] Cui, G. (1993) Advertising English 3000. Beijing Institute of Technology Press, Beijing.

[10] Nida, E.A. (1964) Towards a Science of Translating. Shanghai Foreign Language Education Press, Beijing. 